and not the mere imparting of mechanical aptitude for any particular process. Mr. Hardman said further that the Ministry, after discussions with the Department of Scientific and Industrial Research and with the Federation of British Industries, is also seeking to encourage and considerably extend research work in technical colleges, and particularly research work which is directed towards the assistance of local industries.

In reply to questions about the disposal of scientific apparatus and other Government surplus stores, Mr. Hardman said that the Ministry is working in co-ordination with Government Departments selling surplus stores, and has its own representatives on the appropriate committees. The use of surplus stocks for the purposes of technical education has not been overlooked. Although the debate centred largely around the Percy Report, and it was admitted that the technical colleges and institutions of Britain should be developed so as to provide for a much bigger percentage of the school population, the question of technical education in relation to the universities was not pursued, and it is a sad reflexion on departmentalism that Mr. Hardman was unable to reply to numerous questions about the position of the universities, because they come more within the purview of the Treasury than of the Ministry of Education. Mr. Durbin's request that the Parliamentary Secretary should satisfy himself that the Ministry has communicated to the universities with sufficient clarity and force the essential need which the universities can meet in technical education, and that the universities are fully aware of the extent of that need, was virtually unanswered.

\section{Seismic Sea Wave of April 2}

ON April 2 a strong tunami, beginning near Unimak in the Aleutians, ranged the Pacific Coast of the Americas and the Pacific Islands to distances of 7,000 miles. At Scotch Cape Lighthouse, near Unimak, it is reported to have attained a height of $100 \mathrm{ft}$. and to have killed ten people there. The effects were probably greatest at Hilo, Hawaii, at a distance of gome 2,040 miles from Unimak Island. This town, with a population of 22,000 , was devastated by at least three waves four to six feet high travelling at some 30 knots. Buildings on one side of Kamehameha Avenue were flung against those on the other side. In the town, sixty bodies have so far been recovered and twenty-three in the rest of the Hawaiian Islands. It is feared that the death-roll may reach 150 , and damage is estimated at $£ 2 \frac{1}{2}$ millions. At the time of the disaster, there were two ships in the harbour; one managed to put to sea, but the other, a freighter, was tossed up on the beach. The wave was less strong along the Californian coast, and in the neighbourhood of Arica and Iquique (Chile) it caused some apprehension. During the 24 hours following the Unimak earthquake, there were five strong aftershocks and forty or fifty smaller ones from the same or nearby epicentres.

Tunamis are often caused by the sudden rising or falling of a part of the ocean bed at the time of an earthquake. They are scarcely recognizable out at sea, but on reaching the head of a bay or harbour attain extraordinary heights, sometimes up to $100 \mathrm{ft}$. The outstanding feature of a tunami is its great wavelength-in the Pacific, 100 to $1,000 \mathrm{~km}$.- - and this explains the great distances such waves travel since the wave energy does not decline so rapidly as in ordinary wind waves. The principal period of the Sanriku tunami of June 15, 1896, was 15 minutes, and those of the Krakatoa eruption of August 27, 1883, one hour. The velocity of propagation is related to the depth of water through which the waves pass. The speed across the Pacific is about 450 miles an hour, and across the shallower Atlantic Ocean about 200 miles per hour.

\section{Night Sky in South Africa}

Dr. MARY N. FYSH, of "Canterbury", P.O. Devondale, Cape Province, South Africa, has sent an account of the night sky as seen from the high veldt country formerly known as Stellaland, in the Vryburg district of South Africa. There are probably few regions in the world better suited for such observations. Dr. Fysh states that the lightest film of cloud, such as will not hide even the faintest stars, is enough to obscure some of the appearances which she describes. Most of these will be recognized by astronomers and meteorologists as examples of the aurora, and a few perhaps refer to noctilucent clouds high up in the stratosphere.

Dr. Fysh writes : "On every clear night, soon after the brightest stars have appeared, on locking attentively straight overhead, one can see a fine pattern as if formed by tiny cloudlets, very delicately rosecoloured against the evening blue. Sil John Herschel, who noticed what seems to be the same appearance on the great nebula in Orion, describes it as 'like the breaking up of a mackerel sky'. The pattern gradually spreads outwards, around and downwards, until eventually the whole sky is encanopied as it were, the mottling being as a rule larger and more spaced out as it nears the horizon, and the colour changing from rose to lilac, then to lavender-grey or neutral against the pale primrose in the west where the sun has gone down. A little later, the zodiacal light interposes its softly glowing white, or faintly violet, pyramid between one's vision and the pattern, which is still to be seen overhead and in the easterm and southern sky. Sometimes, however, when the zodiacal light is less bright, both may be seen simultaneously, causing an observer to wonder whether the zodiacal light is seen through the pattern, or the pattern through the light. But we have only seen it thus on one occasion. As one watches, the pattern can often be seen to change a little, the mottling moving apart and closing up, as if blown hither and thither by some mighty wind, yet the whole held together in much the same delicate pattern. It is not always the same colour. As the night advances, the rose colour fades into lilac, then to a faint neutral or pearly grey. Or occasionally it is seen a quite deop red, against a dark, blue-black background. When this happens, it is striking enough to call forth exclamations of wonder from a casual observer, the red being very noticeable. The phenomenon is best seen out on the open veldt, far from the atmosphere of towns. There it can be studied at leisure, and its varying appearances under different conditions noted and recorded. Thus on monlight nights the colour varies from pearl to silver, though then the rose colour may also sometimes be seen at its best; while under the mighty arch of the Milky Way we have seen it looking like myriads of soft snowflakes, so that one almost thinks there is a snowstorm going on up there." 